\title{
Value ofMulti-Detector Computed Tomography in Diagnosis of Esophageal and Fundal Varices in Cirrhotic Patients
}

Magdy Abdel Mawgod, Mohammed E. El-Shewi, Mohammad A. Al-Shatouri, Mohamed A. Abozeid

Department of Hepatology, Gastroenterology and Infectious diseases, Benha faculty of medicine, Benha University, Egypt.

Correspondence to: Mohamed A. Abozeid, Department of Hepatology, Gastroenterology and Infectious diseases, Benha faculty of medicine, Benha University, Egypt

Email:

m.abouzaid2021@yahoo.com

Received: 24 March 2021

Accepted: 11 May 2021

\begin{abstract}
Background: Esophageal varices is one of the most common complications of liver cirrhosis, which lead to hematemesis with high morbidity and mortality rates. This study aimed to assess the role of triphasic computed tomography (CT) scan in detection and grading of esophageal varices $(\mathrm{EV})$ and gastric varices $(\mathrm{GV})$ compared to endoscopy. Patients and methods: A cross-sectional study was conducted on 35 patients ( 26 male \& 9 female) who had cirrhosis. All patients were referred to perform triphasic abdominal CT scan then upper gastro-intestinal (UGI) endoscopy. Results: We have noticed that there is only 1 patient had oesophageal varices confirmed by UGI endoscopy not seen in CT. while there were 15 patients confirmed by endoscopy and CT. There is only 1 patient had gastric varix confirmed by UGI endoscopy not seen in CT. while
\end{abstract} there were 8 patients confirmed by endoscopy and CT. CT has 88.9 sensitivity comparing to endoscopy and 100 specificity with 97.14 accuracy with highly significant $p$ value $(p<0.05)$. CT detected 8 positive cases of gastric varices and one negative case while EGD detected 9 positive cases. So CT has 88.9 sensitivity comparing to endoscopy and 100 specificity with 97.14 accuracy with highly significant $p$ value $(\mathrm{p}<0.05)$. Conclusion: CT scan could be used as independent method for diagnosis of gastric and esophageal varices.

Keywords: Multi-Detector; CT; Esophageal; Varices; Cirrhotic Patients

\section{Introduction}

The gold standard in diagnosis of esophageal varices remains esophagogastroduodenoscopy (EGD) (1). Therefore, there has been substantial interest in developing a reliable non- 
elastography and esophageal capsule endoscopy (2).

Since CT imaging is non-invasive, does not require sedation, and allows review and accurate measurement of variceal size, it is reasonable to believe that $\mathrm{CT}$ would be better tolerated than endoscopy by most patients (3).

Multi-detector computed tomography (MDCT) is an effective screening tool for differentiating large gastric varices (4) also, MDCT can be used as an important tool for detecting submucosal and perigastric varices (5), however the importance of MDCT in screening of EV and its grading is abandoned.

The aim of this study is to focus on the value of MD-CT esophagography in diagnosis of esophageal and fundal varices.

\section{Patients and Methods}

The study was conducted on 35 patients according to the statistical sample size which attended the outpatient clinic and the inpatient section of the Gastroenterology \& Hepatology department of Ismailia General Hospital after Benha scientific committee approval and patient medical consent, during the period from May 2019 to May 2020 .

The study was a cross-sectional study one for evaluation of the role of MD-CT in the diagnosis of esophageal \& gastric varices.

The study protocol was approved by the Ethics Committee of the Benha University, Faculty of Medicine.

\section{Inclusion criteria}

- Patients with liver cirrhosis diagnosed by clinically: Signs and symptoms of decompensated cirrhosis include abdominal swelling, jaundice. Laboratory: elevated hepatic transaminase levels (e.g., ALT, AST). Elevation of serum PT or International Normalized Ratio (INR). Ultrasonography: small liver size, bluntness of the liver edge, coarseness of the liver parenchyma, nodularity of the liver surface, spleen size, ascites, Hepato-cellular carcinoma and Budd-Chiari syndrome (1).

\section{Exclusion criteria:}

- Patients with history of gastrointestinal bleeding. 
- Patients with history of previous prophylactic variceal ligation or variceal injection.

- Patients with known hypersensitivity to intravascular contrast agent.

\section{All patients were subjected to thorough} history taking, clinical examinations and the following:

1. Complete blood count (CBC): Hemoglobin (HB) - White blood cells (WBC) - Platelet count (PLT).

2. Liver tests: prothrombin time (PT), prothrombin concentration, INR, serum albumin, bilirubin.

3. Liver enzymes: ALT, AST.

4. Hepatitis markers: HBsAg, HCVAb by Enzyme-Linked Immunosorbent Assay (ELISA).

5. Kidney function tests: creatinine and blood urea.

6. Pelvi-abdominal ultrasound

7. $\mathrm{MD}-\mathrm{CT}$

8. Esophagogastroduodenoscopy

\section{Statistical analysis}

Gathered data was processed using version SPSS 17 (statistical package for scientific studies). Quantitative data was expressed as median or means \pm standard deviation (SD) as appropriate. Qualitative data was expressed as frequency (numbers) and percentages. The results for all categorical variables were given in the form of rates (\%). Student $t$ test was used to test significance of difference for quantitative variables that follow normal distribution. Chi Squares was use to compare between different groups. Fisher's Exact or Monte Carlo correction test was used to chisquare when more than $20 \%$ of the cells have expected count less than 5. Mann Whitney test was used for abnormally distributed quantitative variables, to compare between two studied groups. Regression was used to detect the most independent/ affecting factor for affecting evidence of esophageal varices.

\section{Results:}

Most patients $26(74 \%)$ were male and the mean age of patients was 55.23 \pm 8.46 year. (Table 1)

Twenty three patients (65.7) were HCV $+\mathrm{ve}$, nine patients were bilhariziasis + $\mathrm{HCV}$ while only 2 patients were $\mathrm{HBsAg}$ +ve. The mean of ALT and AST was 55.51 and $79.17 \mathrm{IU} / \mathrm{ml}$ respectively. The mean of serum albumin was $3.37 \mathrm{~g} / \mathrm{dl}$ while the mean of serum bilirubin was 
$2.1 \mathrm{mg} / \mathrm{dl}$. The mean of Creatinine was 0.94. The mean of Alfa-fetoprotain (AFP) was 1023.33 ranging from 3.4 12200. (Table 2)

Regarding liver size: Twenty eight patients $(80 \%)$ had average liver size while 7 patients had shrunken. Regarding liver echogenicity: Twenty two patients (62.9) had coarse echogenicity while 13 patients $(37.1 \%)$ had homogenous echogenicity. Regarding spleen size: Twenty patients (57.1\%) had enlarged spleen size and 15 patients (42.9\%) had average spleen size with mean of spleen span 14.18 \pm 3.49 cm. (Table 3)
Regarding evidence of esophageal varices: Sixteen patients $(45.7 \%)$ had evidence of esophageal varices. Regarding evidence of gastric varices: Nine patients $(25.7 \%)$ had evidence of gastric varices. In 16 patients with esophageal varices, most of them were male (14) and the mean age of those patients was 58.50 year. In 16 patients with esophageal varices, the mean of ALT and AST was 71.81 and 106.44 IU/ml respectively. The mean of serum albumin was $2.94 \mathrm{~g} / \mathrm{dl}$ while the mean of serum bilirubin was $2.99 \mathrm{mg} / \mathrm{dl}$. In 16 patients with esophageal varices, the mean of AFP was 2044.2 ranging from 3.40 to 12200 . (Table 4)

Table 1. Demographic data of the studied patients $(\mathrm{N}=35)$ :

\begin{tabular}{lcc}
\hline Personal data & \multicolumn{2}{c}{ The studied group (35) } \\
& No & \% \\
\hline Gender & 26 & 74.3 \\
Male & 9 & 25.7 \\
Female & \multicolumn{2}{c}{$55.23 \pm 8.46(38-70)$} \\
Age mean \pm SD (range) (yrs) & \multicolumn{2}{c}{} \\
Occupation & 11 & 31.4 \\
employer & 4 & 11.4 \\
worker & 7 & 20.0 \\
farmer & 13 & 37.1 \\
other & \multicolumn{2}{|c}{} \\
Residence & \multicolumn{2}{c}{} \\
Urban & 19 & 54.3 \\
Rural & 16 & 45.7 \\
Smoking & & 60.0 \\
Yes & 21 & 40.0 \\
No & 14 & \\
\hline
\end{tabular}


Table 2. History of present illness and investigations of the studied patients $(\mathrm{N}=35)$ :

\begin{tabular}{|c|c|c|c|}
\hline History of present illness & & e studied & $(35)$ \\
\hline & & & $\%$ \\
\hline $\mathrm{HCV}$ & & & 65.7 \\
\hline $\mathrm{HBV}$ & & & 5.7 \\
\hline Bilharziasis $+\mathrm{HCV}$ & & & 25.7 \\
\hline Others & & & 2.9 \\
\hline & Mean & $\pm \mathrm{SD}$ & Range \\
\hline $\operatorname{ALT} \quad(\mathrm{IU} / \mathrm{mI})$ & 55.51 & 21.81 & $19-112$ \\
\hline AST $(\mathrm{IU} / \mathrm{ml})$ & 79.17 & 34.27 & $22-165$ \\
\hline S. albumin $(\mathrm{gm} / \mathrm{dl})$ & 3.37 & 0.56 & $2.2-4.5$ \\
\hline T. bilirubin $(\mathrm{mg} / \mathrm{dl})$ & 2.1 & 1.04 & $0.7-4.7$ \\
\hline $\mathrm{Cr} \quad(\mathrm{mg} / \mathrm{dl})$ & 0.94 & 0.20 & $0.5-1.3$ \\
\hline AFP $(\mathrm{ng} / \mathrm{ml})$ & 1023.33 & 2368.0 & $3.4-12200$ \\
\hline
\end{tabular}

Table 3. Abdominal US (liver size and echogenicity) in the studied patients $(\mathrm{N}=35)$ :

\begin{tabular}{|c|c|c|}
\hline \multirow[t]{2}{*}{ Abdominal US } & \multicolumn{2}{|c|}{ The studied group $(\mathrm{N}=35)$} \\
\hline & No & $\%$ \\
\hline Liver size & 28 & 80 \\
\hline Average & 7 & 20 \\
\hline \multicolumn{3}{|l|}{ Shrunken } \\
\hline \multicolumn{3}{|l|}{ Liver echogenicity } \\
\hline Homogenous & 13 & 37.1 \\
\hline Coarse & 22 & 62.9 \\
\hline \multicolumn{3}{|l|}{ Hepatic focal lesion } \\
\hline Yes & 27 & 77.1 \\
\hline No & 8 & 22.9 \\
\hline \multicolumn{3}{|c|}{ No of hepatic focal lesions (27) } \\
\hline Solitary & 14 & 51.9 \\
\hline Multiple & 13 & 48.1 \\
\hline $\begin{array}{l}\text { Size of hepatic focal lesions } \\
\text { mean } \pm \text { SD (range) }\end{array}$ & \multicolumn{2}{|c|}{$4.83 \pm 2.45(1.5-10.0)$} \\
\hline \multicolumn{3}{|c|}{ Site of hepatic focal lesions (27) } \\
\hline Rt & 11 & 40.7 \\
\hline $\mathbf{L t}$ & 6 & 22.2 \\
\hline Both & 10 & 37.0 \\
\hline \multicolumn{3}{|c|}{ Echogenicity of hepatic focal lesions (27) } \\
\hline Hypoechoic & 26 & 96.3 \\
\hline Isoechoic & 0 & 0.0 \\
\hline Hyperechoic & 1 & 3.7 \\
\hline P.V. diameter & \multirow{2}{*}{\multicolumn{2}{|c|}{$10.86 \pm 2.71(5-16)$}} \\
\hline mean $\pm \mathrm{SD}($ range $)$ & & \\
\hline P.V.T. & 3 & 8.6 \\
\hline Ascites & 10 & 28.6 \\
\hline $\begin{array}{l}\text { Spleen span } \\
\text { mean } \pm \mathbf{S D} \text { (range) }\end{array}$ & \multicolumn{2}{|c|}{$14.18 \pm 3.49(9-22)$} \\
\hline Spleen size & & \\
\hline Enlarged & 20 & 57.1 \\
\hline Average & 15 & 42.9 \\
\hline
\end{tabular}


Table 4. Esophageal varices by upper GI endoscopy and personal data $(\mathrm{N}=35)$

\begin{tabular}{|c|c|c|c|c|c|c|}
\hline & \multicolumn{4}{|c|}{$\begin{array}{c}\text { Evidence of esophageal varices } \\
\text { by endoscopy }\end{array}$} & \multirow{3}{*}{ Test of Sig. } & \multirow{3}{*}{$\mathbf{p}$} \\
\hline & \multicolumn{2}{|c|}{$\begin{array}{c}\text { Yes } \\
(\mathrm{N}=16)\end{array}$} & \multicolumn{2}{|c|}{$\begin{array}{c}\text { No } \\
(\mathbf{N}=19)\end{array}$} & & \\
\hline & No. & $\%$ & No. & $\%$ & & \\
\hline Gender & & & & & & \\
\hline Male & 14 & 87.5 & 12 & 63.2 & $\chi^{2}=$ & ${ }^{F E} \mathrm{p}=$ \\
\hline Female & 2 & 12.5 & 7 & 36.8 & 2.694 & 0.135 \\
\hline Age & \multirow{3}{*}{\multicolumn{2}{|c|}{$\begin{array}{c}69.0-43.0 \\
58.19 \pm 7.27 \\
58.50\end{array}$}} & & & & \\
\hline Min. - Max. & & & \multirow{2}{*}{\multicolumn{2}{|c|}{$\begin{array}{c}70.0-38.0 \\
52.74 \pm 8.77 \\
51.0\end{array}$}} & & \\
\hline $\begin{array}{l}\text { Mean } \pm \text { SD } \\
\text { Median }\end{array}$ & & & & & 1.978 & 0.056 \\
\hline \multicolumn{7}{|l|}{ Occupation } \\
\hline Employer & 3 & 18.8 & 8 & 42.1 & & \\
\hline Worker & 1 & 6.3 & 3 & 15.8 & $\chi^{2}=$ & ${ }^{\mathrm{MC}} \mathrm{p}=$ \\
\hline Farmer & 7 & 43.8 & 0 & 0.0 & $10.872^{*}$ & $0.009 *$ \\
\hline others & 5 & 31.3 & 8 & 42.1 & & \\
\hline \multicolumn{7}{|l|}{ Residence } \\
\hline Urban & 7 & 43.8 & 12 & 63.2 & $\chi^{2}=$ & \multirow{2}{*}{0.251} \\
\hline Rural & 9 & 56.3 & 7 & 36.8 & 1.318 & \\
\hline \multicolumn{7}{|l|}{ Smoking } \\
\hline Yes & 11 & 68.8 & 10 & 52.6 & $\chi^{2}=$ & \multirow{2}{*}{0.332} \\
\hline No & 5 & 31.3 & 9 & 47.4 & 0.940 & \\
\hline
\end{tabular}

$\chi^{2}$ : Chi square test, FE: Fisher Exact, MC: Monte Carlo, t: Student t-test, p: $p$ value for association

$*$ : Statistically significant at $\mathrm{p} \leq 0.05$. between different categories.

Table 5. Detection of EV and GV by UGI endoscopy and CT

\begin{tabular}{|c|c|c|c|c|c|c|}
\hline & \multicolumn{2}{|l|}{ CT } & \multicolumn{2}{|c|}{ UGI endoscopy } & \multirow{2}{*}{ Statistical test } & \multirow{2}{*}{$P$ value } \\
\hline & NO. & $\%$ & NO. & $\%$ & & \\
\hline \multicolumn{7}{|c|}{ Evidence of EV } \\
\hline Yes & 15 & 42.8 & 16 & 45.7 & \multirow[t]{2}{*}{$X 2=0.53$} & \multirow[t]{2}{*}{0.47} \\
\hline No & 20 & 57.1 & 19 & 54.3 & & \\
\hline \multicolumn{7}{|l|}{ If yes } \\
\hline High risk & 12 & 80 & 14 & 87.5 & \multirow{3}{*}{$\mathrm{FET}=0.07$} & \multirow{2}{*}{0.80} \\
\hline Low risk & 3 & 20 & 2 & 12.5 & & \\
\hline \multicolumn{6}{|c|}{ Evidence of GV } & \\
\hline Yes & 8 & 22.9 & 9 & 25.7 & \multirow{2}{*}{$\mathrm{X} 2=0.08$} & \multirow{2}{*}{0.78} \\
\hline No & 27 & 77.1 & 26 & 74.3 & & \\
\hline
\end{tabular}

Table 6. Validity of CT as prediction of EV:

\begin{tabular}{|c|c|c|c|c|c|c|c|c|c|}
\hline \multirow[t]{3}{*}{ CT of EV } & \multicolumn{4}{|c|}{ UGI endoscopy of EV } & \multirow{3}{*}{ : } & \multirow{3}{*}{ 节 } & \multirow{3}{*}{$\frac{\vec{a}}{a}$} & \multirow{3}{*}{$\vec{z}$} & \multirow{3}{*}{ 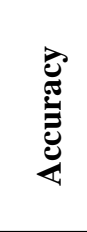 } \\
\hline & \multicolumn{2}{|c|}{$\begin{array}{c}\text { No } \\
(n=19)\end{array}$} & \multicolumn{2}{|c|}{$\begin{array}{c}\text { Yes } \\
(n=16)\end{array}$} & & & & & \\
\hline & No. & $\%$ & No. & $\%$ & & & & & \\
\hline No & 19 & 100.0 & 1 & 6.25 & & & & & \\
\hline Yes & 0 & 0.0 & 15 & 93.75 & 90.10 & 100.0 & 100.0 & 90.0 & 91.14 \\
\hline$\chi^{2}(\mathbf{p})$ & \multicolumn{4}{|c|}{$31.17\left(<0.001^{* *}\right)$} & & & & & \\
\hline
\end{tabular}

$\chi^{2}$ : Chi square test, $\mathrm{p}: \mathrm{p}$ value for association between different categories.

$*$ : Statistically significant at $\mathrm{p} \leq 0.05 . \quad * *$ : Statistically significant at $\mathrm{p} \leq 0.01$ 
Table 7. Validity of CT as prediction of GV:

\begin{tabular}{|c|c|c|c|c|c|c|c|c|c|}
\hline \multirow{3}{*}{ CT of GV } & \multicolumn{4}{|c|}{ UGI endoscopy of GV } & \multirow{3}{*}{ : } & \multirow{3}{*}{ : } & \multirow{3}{*}{$\vec{a}$} & \multirow{3}{*}{$\frac{1}{\mathbf{z}}$} & \multirow{3}{*}{ 异 } \\
\hline & \multicolumn{2}{|c|}{$\begin{array}{c}\text { No } \\
(n=26)\end{array}$} & \multicolumn{2}{|c|}{$\begin{array}{c}\text { Yes } \\
(\mathbf{n}=9)\end{array}$} & & & & & \\
\hline & No. & $\%$ & No. & $\%$ & & & & & \\
\hline No & 26 & 100.0 & 1 & 11.1 & & & & & \\
\hline Yes & 0 & 0.0 & 8 & 88.9 & 00.09 & 100.0 & 100.0 & 30.50 & 91.14 \\
\hline$\chi^{2}(\mathbf{p})$ & \multicolumn{4}{|c|}{$25.13\left(<0.001^{* *}\right)$} & & & & & \\
\hline
\end{tabular}

$\chi^{2}$ : Chi square test, $\mathrm{p}$ : $\mathrm{p}$ value for association between different categories.

$*$ : Statistically significant at $\mathrm{p} \leq 0.05 . \quad * *$ : Statistically significant at $\mathrm{p} \leq 0.01$.

Regarding evidence of esophageal varices: there were 15 patients had evidence of esophageal varices detected by C.T. "of whom 12 patients with high risk varices and 3 patients with low risk varices" while there were 16 patients had evidence of esophageal varices detected by UG endoscopy "of whom 14 patients with high risk varices and 2 patients with low risk varices". According to the previous results; CT has 93.75 sensitivity comparing to endoscopy and 100 specificity with 97.14 accuracy with highly significant $\mathrm{p}$ value $(\mathrm{p}<0.05)$. Regarding evidence of gastric varices: only 8 patients had evidence of gastric varices detected by C.T. while there were 9 patients had evidence gastric varices detected by UG endoscopy. (Table 5)

According to the previous results; CT has 88.9 sensitivity comparing to endoscopy and 100 specificity with 97.14 accuracy with highly significant $p$ value $(\mathrm{p}<0.05)$. CT detected 8 positive cases of gastric varices and one negative case while EGD detected 9 positive cases. So CT has 88.9 sensitivity comparing to endoscopy and 100 specificity with 97.14 accuracy with highly significant $\mathrm{p}$ value $(\mathrm{p}<0.05)$. (Table 6 \& 7).

\section{Discussion}

The present study included (35) patients with cirrhosis (26) males (74.3\%) and (9) females $(25.7 \%)$. So male affection is more predominant than female in agreement with other studies (6) where male patients were $74 \%$ and female patients were $26 \%$.

In this study, as regarding the mean age of patients was 55.23 \pm 8.46 agreement with other researches $(7)$, where $(65 \%)$ of 
cirrhotic patients aged between 45 and 65 years.

In this study, more than $90 \%$ of patients had viral hepatitis which is much more than what was reported in 2017 (8), that viral hepatitis was proved in $14 \%$ of patients and this was said to be because viral hepatitis (especially $\mathrm{HCV}$ ) is the most common cause of liver cirrhosis in Egypt (9).

In this study, as regarding CT findings for esophageal varices, cases were classified into: Group I (no varices): Includes 20 patients with no esophageal varices (57.1\%). Group II (with varices): Includes 15 patients with esophageal varices (42.8\%) and consists of: Group II-a (low risk varices): Includes 12 patients with low risk varices $(80 \%)$. Group II-b (high risk group): Includes 3 patients with high risk varices (20\%). While upper endoscopy findings were as following: Group I (no varices): Includes 19 patients with no esophageal varices (54.3\%). Group II (with varices): Includes 16 patients with esophageal varices (45.7\%) and consists of : Group II (low risk varices): Includes 2 patients with low risk varices (12.5\%). Group III (high risk group): Includes F2 and F3 degrees of $\mathrm{EV}$ were detected in 14 patients $(87.5 \%)$.

CT scan had a sensitivity of (93.75\%), a specificity of $(100 \%)$, in comparison with upper GI endoscopy as the reference standard method.

The same conventional protocol was used by others (6) where the overall CT sensitivity was (96\%), specificity (100\%), in comparison to the gold standard upper endoscopy.

Our study was in agreement other study (10) which set that CT is highly sensitive (sensitivity 93\%) as compared to upper GI endoscopy in detecting esophageal varices.

Sensitivity (92\%), specificity (84\%) less than our study, was gained from some studies (11). This mostly because the esophageal lumen was insufflated in order to visualize the varices. This procedure had a negative effect on the ability to visualize and accurately measure small varices.

In this study, as regarding CT findings for gastric varices, cases were classified into: Group I (no varices): Includes 27 patients with no gastric varices $(77.1 \%)$. Group II (with varices): Includes 8 patients with gastric varices (22.9\%). While upper endoscopy findings were as following: Group I (no varices): Includes 26 patients with no gastric varices (74.3\%). Group II (with varices): Includes 9 patients with gastric varices (25.7\%).

CT scan had a sensitivity of (88.89\%), a specificity of (100\%), in comparison 
with upper GI endoscopy as the reference standard method.

The same conventional protocol was used by others (12) where the overall CT sensitivity was (95\%), in comparison to the gold standard upper endoscopy.

It was stated that the sensitivity of $\mathrm{CT}$ in detecting gastric varices was $87 \%$ (3). In addition, a significant number of gastric varices, peri-esophageal varices, and extraluminal pathology were identified by CT that was not identified by endoscopy.

A conclusion was set that routine liver CT protocol is sufficient for evaluation of esophageal varices in cirrhotic patients without adding thin section reconstruction images (13).

$\mathrm{CT}$ is considered a less invasive, better tolerated and less expensive test with high sensitivity and specificity for detection of large varices would allow for better selection of patients to undergo endoscopic intervention for large esophageal varices (14).

So MD-CT esophagography is a good alternative diagnostic tool to conventional EGD for screening of esophageal varices and grading of its risk of bleeding in cirrhosis. The role of abdominal triphasic CT scan, to screen the liver for the presence of focal lesions (that are not uncommon with cirrhosis) and to assess portal hypertension signs, is of higher cost-benefit as an initial full examination method in patients with cirrhosis (multi-purpose) than that of upper endoscopy for screening and grading of esophageal varices.

\section{Conclusion}

EGD stills the gold standard in EV and GV diagnosis and therapy. Triphasic CT abdomen is a good noninvasive alternative method for detection and grading of the varices. The good compliance to CT scan compared to endoscopy allows better results in surveillance and early detection of varices. CT scan minimizes the over use of diagnostic endoscopy and evaluates other items that cannot be evaluated by endoscopy e.g. liver status, presence of HCC, para-esophageal varices and other signs of portal hypertension.

\section{References}

1) Garcia-Tsao G, Sanyal AJ, Grace ND, Carey W. the American Association for the Study of Liver Diseases, the Practice Parameters Committee of the American College of Gastroenterology.

Hepatology.vol.46(3),pp.922-38,2007.

2) de Franchis R. Updating consensus in portal hypertension: report of the Baveno III Consensus Workshop on definitions, methodology and therapeutic strategies in portal hypertension. Journal of hepatology. 2000 Nov 1;33(5):846-52.

3) Perri RE, Chiorean MV, Fidler JL, Fletcher JG, Talwalkar JA, Stadheim L, et al. A 
prospective evaluation of computerized tomographic (CT) scanning as a screening modality for esophageal varices. Hepatology. 2008 May;47(5):1587-94.

4) Zhu K, Meng X, Pang P, Qian J, Shen M, Hu B, Shan H. Gastric varices in patients with portal hypertension: evaluation with multidetector row CT. Journal of clinical gastroenterology. 2010 May 1;44(5):e10815.

5) Zhu KS, Meng XC, Zhang JS, Guan SH, Li ZR, He KK, Pang PF, Jiang ZB, Huang MS, Shan $\mathrm{H}$. The role of multi-detector row $\mathrm{CT}$ in the diagnosis and hemodynamic studies of gastric varices in portal hypertension. Zhonghua yi xue za zhi. 2007 Dec $1 ; 87(46): 3251-5$.

6) Moftah SG, Kamal S, Hanna AT. CT esophagography: non invasive screening and grading of esophageal varices in cirrhosis. The Egyptian Journal of Radiology and Nuclear Medicine. 2014 Jun 1;45(2):263-70.

7) Kim H, Choi D, Gwak GY, Lee JH, Lee SJ, Kim SH, et al. High-risk esophageal varices in patients treated with locoregional therapies for hepatocellular carcinoma: evaluation with regular follow-up liver CT. Digestive diseases and sciences. 2009 Oct 1;54(10):2247.

8) Calame $\mathrm{P}$, Ronot $\mathrm{M}$, Bouveresse $\mathrm{S}$, Cervoni JP, Vilgrain V, Delabrousse É. Predictive value of CT for first esophageal variceal bleeding in patients with cirrhosis: value of para-umbilical vein patency. European journal of radiology. 2017 Feb 1;87:45-52.
9) Gomaa A, Allam N, Elsharkway A, El Kassas M, Waked I. Hepatitis C infection in Egypt: prevalence, impact and management strategies. Hepatic medicine: evidence and research. 2017;9:17.

10) El-Assaly H, Metwally LI, Azzam H, SeifElnasr MI. A comparative study of multidetector CT portography versus endoscopy in evaluation of gastro-esophageal varices in portal hypertension patients. Egyptian Journal of Radiology and Nuclear Medicine. 2020 Dec;51(1):1-0.

11) Kim YJ, Raman SS, Yu NC, To'o KJ, Jutabha R, Lu DS. Esophageal varices in cirrhotic patients: evaluation with liver CT. American Journal of Roentgenology. 2007 Jan;188(1):139-44.

12) Willmann JK, Weishaupt $D$, Böhm $T$, Pfammatter T, Seifert B, Marincek B, Bauerfeind P. Detection of submucosal gastric fundal varices with multi-detector row CT angiography. Gut. 2003 Jun $1 ; 52(6): 886-92$.

13) Kim H, Choi D, Gwak GY, Lee JH, Park MK, Lee HI, et al. Evaluation of esophageal varices on liver computed tomography: receiver operating characteristic analyses of the performance of radiologists and endoscopists. Journal of gastroenterology and hepatology. 2009 Sep;24(9):1534-40.

14) Hassan M, Husen $Y$, Summar-un-nisa Abbasi ZH. Diagnostic accuracy of multidetector computed tomography in detection of esophageal varices. Cureus. 2019 Jan;11(1).

To cite this article: Magdy Abdel Mawgod, Mohammed E. El-Shewi, Mohammad A. AlShatouri, Mohamed A. Abozeid. Value ofMulti-Detector Computed Tomography in Diagnosis of Esophageal and Fundal Varices in Cirrhotic Patients. BMFJ2021; 38(2): 580-589. DOI: 10.21608/bmfj.2021.69273.1401 
Benha medical journal, vol. 38, issue 2, 2021 